This item was submitted to Loughborough's Research Repository by the author.

Items in Figshare are protected by copyright, with all rights reserved, unless otherwise indicated.

\title{
Crowd satisfaction at sporting events
}

PLEASE CITE THE PUBLISHED VERSION

http://dx.doi.org/10.1201/b13826-52

PUBLISHER

(C) Taylor \& Francis

VERSION

AM (Accepted Manuscript)

LICENCE

CC BY-NC-ND 4.0

REPOSITORY RECORD

Kendrick, Victoria L., Roger Haslam, and Patrick Waterson. 2019. "Crowd Satisfaction at Sporting Events". figshare. https://hdl.handle.net/2134/12403. 
This item was submitted to Loughborough's Institutional Repository (https://dspace.lboro.ac.uk/) by the author and is made available under the following Creative Commons Licence conditions.

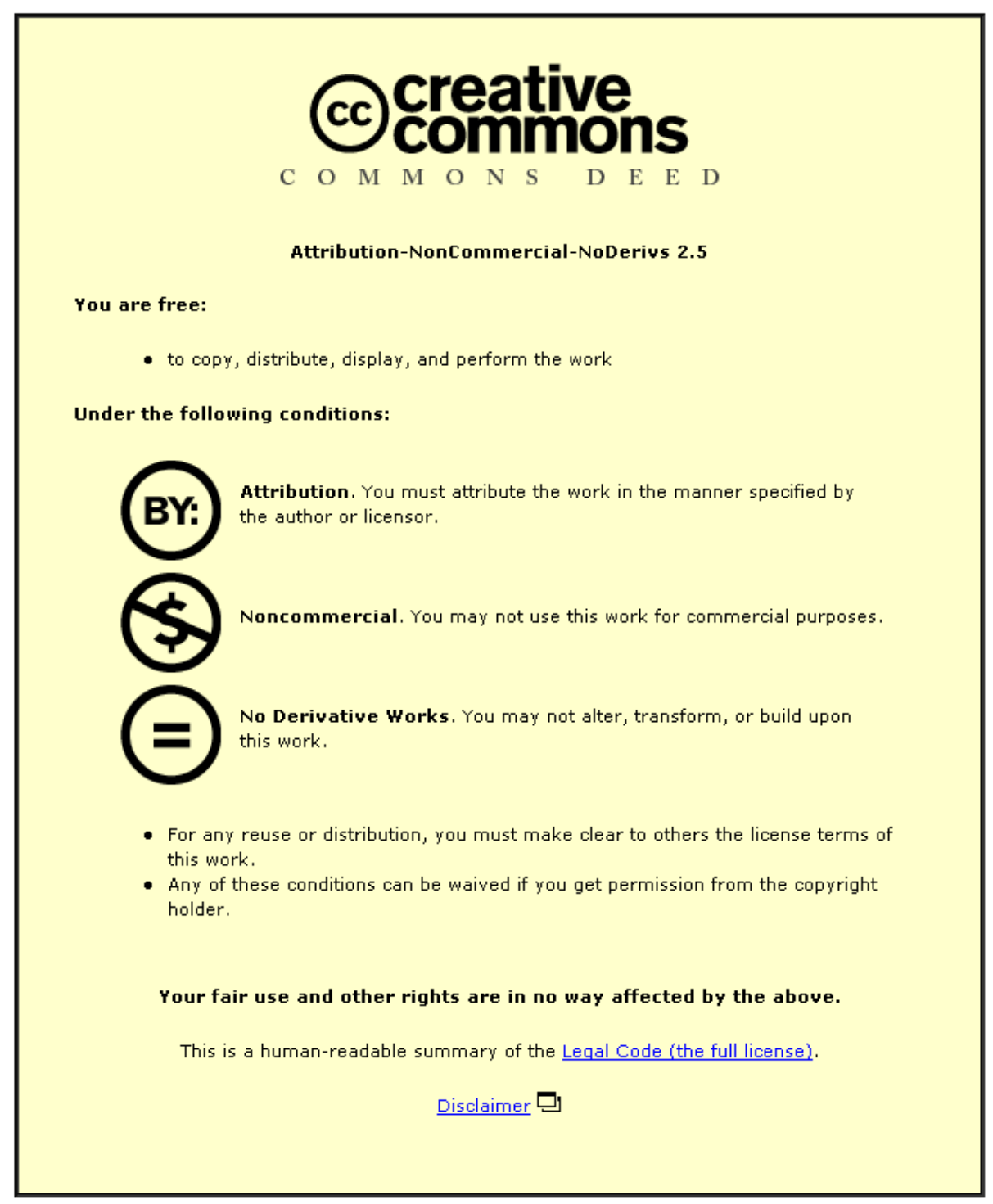

For the full text of this licence, please go to: http://creativecommons.org/licenses/by-nc-nd/2.5/ 


\title{
CROWD SATISFACTION AT SPORTING EVENTS
}

\author{
Victoria L. Kendrick, Roger A. Haslam and Patrick E. Waterson
}

Loughborough Design School, Loughborough University, UK

\begin{abstract}
This paper presents findings from in depth semi-structured interviews with event organisers and deliverers, investigating the organisation, coordination, and security of a variety of spectator sporting events. Safety was identified by those responsible for organising and delivering events as a key priority, with less attention given to user experience, crowd comfort and satisfaction. An evidence based description was developed to embody findings of the current study, illustrating the central issues that influence crowd satisfaction within spectator sporting events: anticipation, facilities, and planning (prior to the event); influences and monitoring (carried out during the event); and reflection (engaged in after the event).
\end{abstract}

\section{Introduction}

Despite the popularity of spectator sporting events, academic research examining how the organisation of crowd events can be enhanced remains relatively underdeveloped (Zhang et al., 2007; Johnson, 2008). Research addressing crowd events has largely focused on crowd safety (Zhen et al., 2008), pedestrian flow modelling (Smith et al., 2009), and event management over recent years (Getz, 2008): with substantial research around public order policing (Reicher et al., 2004; (Drury \& Stott, 2011), and hooliganism prevention (Stott et al., 2008). Consideration of the wellbeing of the crowd, particularly crowd satisfaction, comfort and performance has received less attention (Ryan et al., 2010; Machleit et al., 2000; Berlonghi, 1995). Moreover, the extent to which academic research findings influence the organisation of spectator sporting events is unclear. 


\section{Background}

Prior research by the authors explored the user experience of crowds through focus groups, revealing differences in the factors affecting crowd satisfaction, with age and expectations (Kendrick \& Haslam, 2010). However, venue design, event organisation, and safety and security concerns were found to highly affect crowd satisfaction, irrespective of group differences or crowd environments, showing the importance of these issues for all crowd events, for all crowd members. In light of the findings from the crowd participant focus groups, the current event organiser and event delivery interview study was undertaken, to explore the extent to which organiser actions meet the needs of the user.

This paper presents a subset of findings that form part of a larger study that used ethnography with spectator events of various descriptions, to explore the user experience of crowds. This included a case study of special events within a large UK university (Kendrick et al., 2012). The study presented here focused on the organisation, coordination, and security of a variety of spectator sporting events. The aim was to develop an evidence based description of important factors contributing towards crowd satisfaction.

\section{Method}

Semi-structured interviews were used to investigate the organisation of crowd events, including: approaches and processes used in the planning for crowd situations; attitudes and beliefs regarding crowd satisfaction, comfort, safety, and performance; and commitment to each (Robson, 1993). Interviewees were drawn from relevant stakeholder groups to achieve a structured convenience sample (Bryman, 2004a).

Sporting events encompassed the following crowd types: ambulatory (walking); spectator (watching an activity or event); expressive (emotional release, shouting, chanting); and limited movement (restricted movement) (Berlonghi., 1995).

A standardised interview question set was developed, with the same facilitator leading each interview (approximately 90 minutes each). Interview recordings were subsequently transcribed verbatim, and imported into the qualitative software tool, NVivo (Version 9.0) to enable systematic analysis (Hignett \& Wilson, 2004).

Development of qualitative analysis involved hybrid thematic analysis of interview data, with data driven codes developed, and the identification of emergent overarching themes (Bryman, 2004b). Reliability was enhanced through the systematic review of the data by two independent researchers. 
The study complied with ethical requirements of Loughborough University ethics committee: all interviewees were provided with information about the study and informed consent was obtained.

\section{Results and Discussion}

Eighteen in depth stakeholder interviews were conducted (16 males; 2 females), comprising event organisers; health and safety officers; public and private security officers; and ground stewards. A variety of spectator sporting events were captured (indoor and outdoor), including various: football, rugby, handball, ice-hockey, and athletics events.

Eleven common themes emerged from the data:

- Health and safety,

- Public order,

- Communication,

- Physical environment,

- Public relations,

- Crowd movement,

- Event capacity,

- Facilities,

- Satisfaction,

- Comfort,

- Crowd characteristics.

Safety was seen to be a high priority, due primarily to legal obligations and a desire to protect venue reputation. However, the comfort and satisfaction of the crowd participants often received less attention, with budget considerations cited as a key reason. Additionally, inadequate communication and management systems were in place to ensure compliance with internal procedures. Interviewees highlighted a lack of usable guidance available to assist with the organisation of special events.

Findings from the interviews are summarised in Figure 1, which illustrates six central issues suggested as influencing crowd comfort, performance, safety, and satisfaction with the organisation and delivery of spectator sporting events: anticipation, facilities, and planning (prior to the event); influences and monitoring (carried out during the event); and reflection (engaged after the event). These are explained further below. 


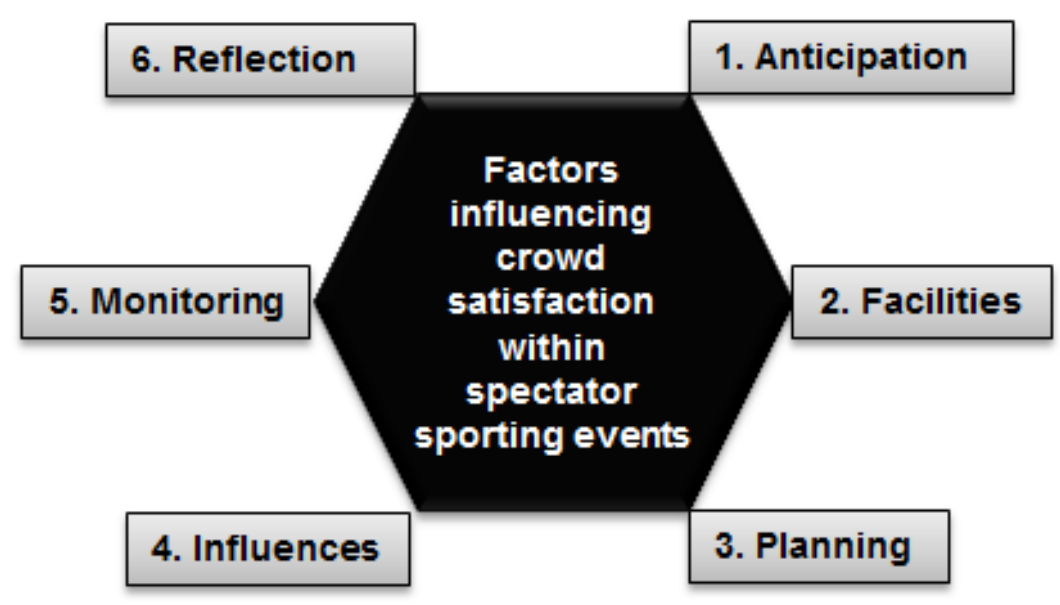

Figure 1: Factors influencing crowd satisfaction within spectator sporting events

Anticipation, facilities, and planning (prior to the event)

These are aspects which take place in advance of the event. Anticipation of the target audience, as well as communication and sharing of knowledge and experience within and between events was limited. There appeared to be a lack of information available to organisers involved in relatively small scale sporting events in particular. Moreover, findings highlight the importance of tailoring crowd planning guidance to different crowd situations, supporting previous research (Berlonghi, 1995; Lee \& Hughes, 2007; Ryan et al., 2010).

Important facility provision was not always well linked to individual event needs, for example in relation to car parking:

"Tescos over the road... supporters also park there... next to the stadium they have a specific number of supporters allocated a specific parking bay number, and they must park there. The problem is that the side streets get clogged with traffic parked up. So there is not a good relationship with the local residents." (Security officer)

Acceptance of ad hoc arrangements such as this suggests a lack of appreciation of user needs as a valid problem requiring attention. Such findings are in line with the underdeveloped literature in this area, with a limited evidence base of knowledge, and usable guidance for planning crowd events (Berlonghi, 1995; Ryan et al., 2010). 
Also planning and attention to crowd user comfort, performance and satisfaction, were often based on "personal judgment" (Event Organiser); and influenced by budget considerations, indicating that financial considerations often take precedence over user comfort and satisfaction.

Event influences and monitoring (carried out during the event)

These relate to the event itself, and the need to adapt rapidly to changing circumstances. Influences including extreme weather were a major concern for those organising and delivering crowd events with, for example, one police officer describing:

"If there was a severe weather problem like ice and snow... then the police would look at it with people from the football ground, and the referee in terms of whether it's safe to play the match. But in terms of the people getting to and from... then the football ground and the police would look at that." (Police Sergeant)

Monitoring capacity during events was an issue stressed during interviews, as highlighted during an interview with an event organiser involved in rugby and athletics events:

"And there will normally be at least two staff on the exits... either to open it up massively if we've got to get people out, which in that kind of venue is very low risk, because it's obviously outside. I mean it's literally a field. I mean you could pull people into the rugby pitch if you really needed to get people away from a specific area." (Event Organiser)

\section{Reflection (after the event)}

Reflection concerns issues that should be resolved following the event. The importance of gaining feedback from all crowd users for example (including all staff working at the event), and implementing the information into future events was recognised throughout interviews. Although post-event learning was recognised as important, this was not always undertaken in practice. One event organiser involved in football and athletics events explained:

"We do, I mean... You see the problem is that I just don't have the time... we got some good feedback on what they thought... but without spending a long time correlating certain aspects... there was only sort of bits we could pull out... But yeah... it's something that we need to do a lot better."(Event Organiser)

The importance of gathering and utilising feedback after events is reflected in research on crowds, although this is predominant in the context of crowd safety rather than other aspects (Lee \& Hughes, 2007). 


\section{Conclusion}

This interview study has identified important factors (anticipation, facilities, planning, influences, monitoring, and reflection) that are important to crowd satisfaction within spectator sporting events. Achieving a positive, high-quality crowd experience is desirable for overall event success, and of benefit to all stakeholders. These findings have fed into further work by the authors, with the goal of developing practical guidance (in the form of a tool for event organiser to use during the planning of crowd events), to aid organisation and enhance the user experience of crowds.

\section{References}

Berlonghi, A. E. (1995). Understanding and planning for different spectator crowds. Safety Science, 18(4), 239-247.

Bryman, A. (2004a). Social Research Methods. Oxford: Oxford University Press. pp183-4.

Bryman, A. (2004b). Social Research Methods. Oxford: Oxford University Press. pp554-5.

Drury, J., \& Stott, C. (2011). Contextualising the crowd in contemporary social science. Contemporary Social Science, 6(3), 275-288.

Getz, D. (2008). Event tourism: Definition, evolution, and research. Tourism Management, 29(3), 403-428.

Hignett, S., \& Wilson, J. R. (2004). The role for qualitative methodology in ergonomics: A case study to explore theoretical issues. Theoretical Issues in Ergonomics Science, 5(6), 473-493.

Johnson, C. W. (2008). Using evacuation simulations for contingency planning to enhance the security and safety of the 2012 olympic venues. Safety Science, 46(2), 302-322.

Kendrick, V. L., Haslam R., A., \& Waterson P., E. (2012). Planning crowd events to achieve high participant satisfaction. Work: A Journal of Prevention, Assessment and Rehabilitation, 41(1), 3223-3226.

Kendrick, V. L., \& Haslam, R. A. (2010). The user experience of crowds - A human factors challenge. Proceedings of the Human Factors and Ergonomics Society Annual Meeting, 54(23), 2000-2004.

Lee, R. S. C., \& Hughes, R. L. (2007). Minimisation of the risk of trampling in a crowd. Mathematics and Computers in Simulation, 74(1), 29-37.

Machleit, K. A., Eroglu, S. A., \& Mantel, S. P. (2000). Perceived retail crowding and shopping satisfaction: What modifies this relationship? Journal of Consumer Psychology, 9(1), 29-42.

Reicher, S., Stott, C., Cronin, P., \& Adang, O. (2004). An integrated approach to crowd psychology and public order policing. Policing - An International Journal of Police Strategies \& Management, 27(4), 558-572.

Robson C (1993) The Real World Research - A Resource for Social Scientists and Practitioner-researchers. Oxford: Blackwell Publications. 
Ryan, C., Shih Shuo, Y. \& Huan, T. (2010). Theme parks and a structural equation model of determinants of visitor satisfaction - Janfusan Fancyworld, taiwan. Journal of Vacation Marketing, 16(3), 185-199.

Smith, A., James, C., Jones, R., Langston, P., Lester, E., \& Drury, J. (2009). Modelling contra-flow in crowd dynamics DEM simulation. Safety Science, 47(3), 395-404.

Stott, C., Adang, O., Livingstone, A., \& Schreiber, M. (2008). Tackling football hooliganism: A quantitative study of public order, policing and crowd psychology. Psychology, Public Policy, and Law, 14(2), 115-141.

Zhang, Q., Liu, M., Wu, C., \& Zhao, G. (2007). A stranded-crowd model (SCM) for performance-based design of stadium egress. Building and Environment, 42(7), 2630-2636.

Zhen, W., Mao, L., \& Yuan, Z. (2008). Analysis of trample disaster and a case study - Mihong bridge fatality in china in 2004. Safety Science, 46(8), 12551270. 